
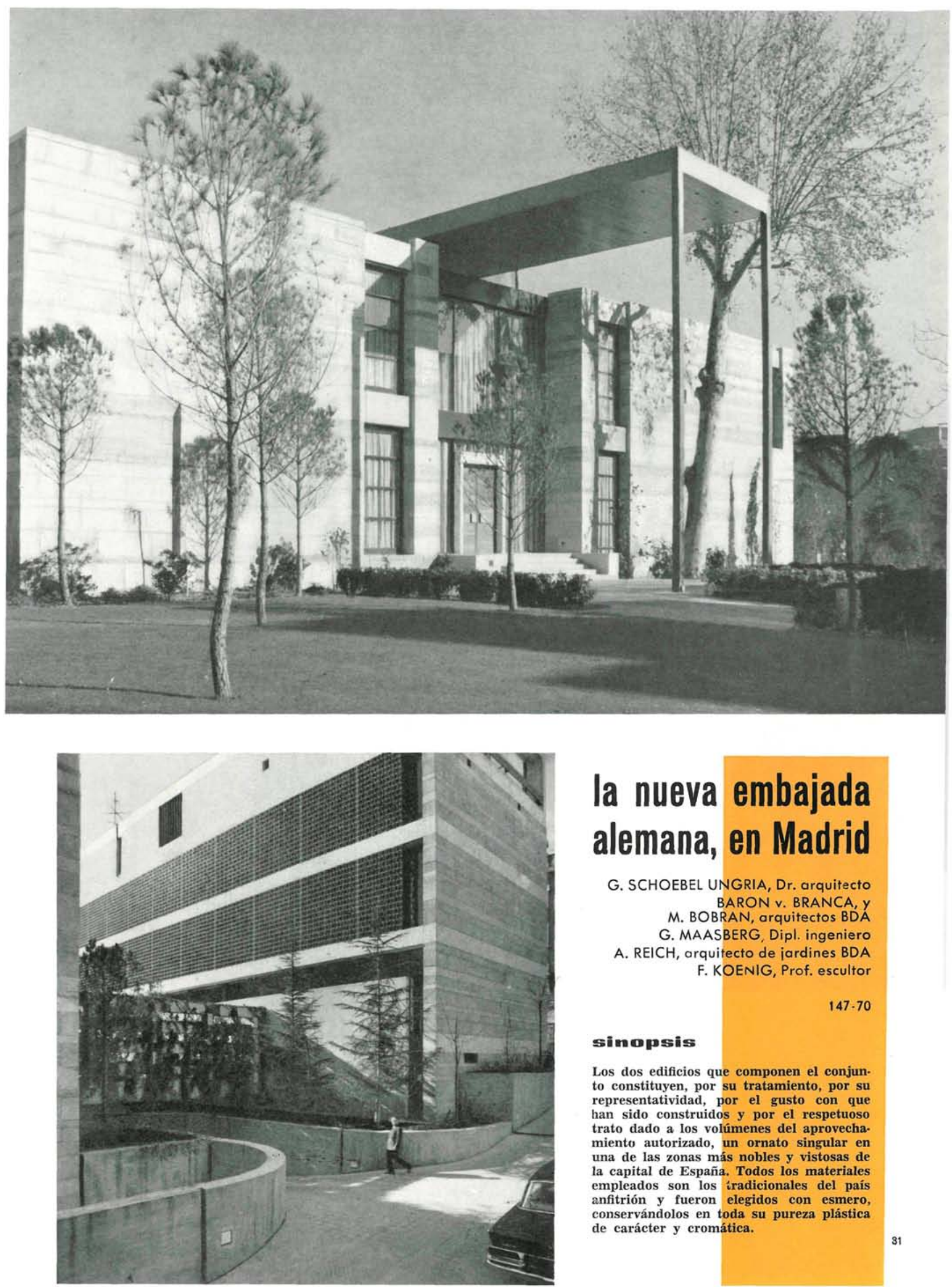

\title{
la nueva embajada alemana, en Madrid
}

G. SCHOEBEL UNGRIA, Dr. arquitecto BARON v. BRANCA, y M. BOBRAN, arquitectos BDA G. MAASBERG Dipl. ingeniero A. REICH, arquitecto de jardines BDA F. KOENIG, Prof. escultor

\section{simopsis}

Los dos edificios que componen el conjun. to constituyen, por su tratamiento, por su representatividad, por el gusto con que han sido construidos y por el respetuoso trato dado a los volúmenes del aprovecha. miento autorizado, un ornato singular en una de las zonas más nobles y vistosas de la capital de España. Todos los materiales empleados son los iradicionales del pais anfitrión y fueron elegidos con esmero, anfitrión y fueron elegidos con esmero, de carácter y cromática. 


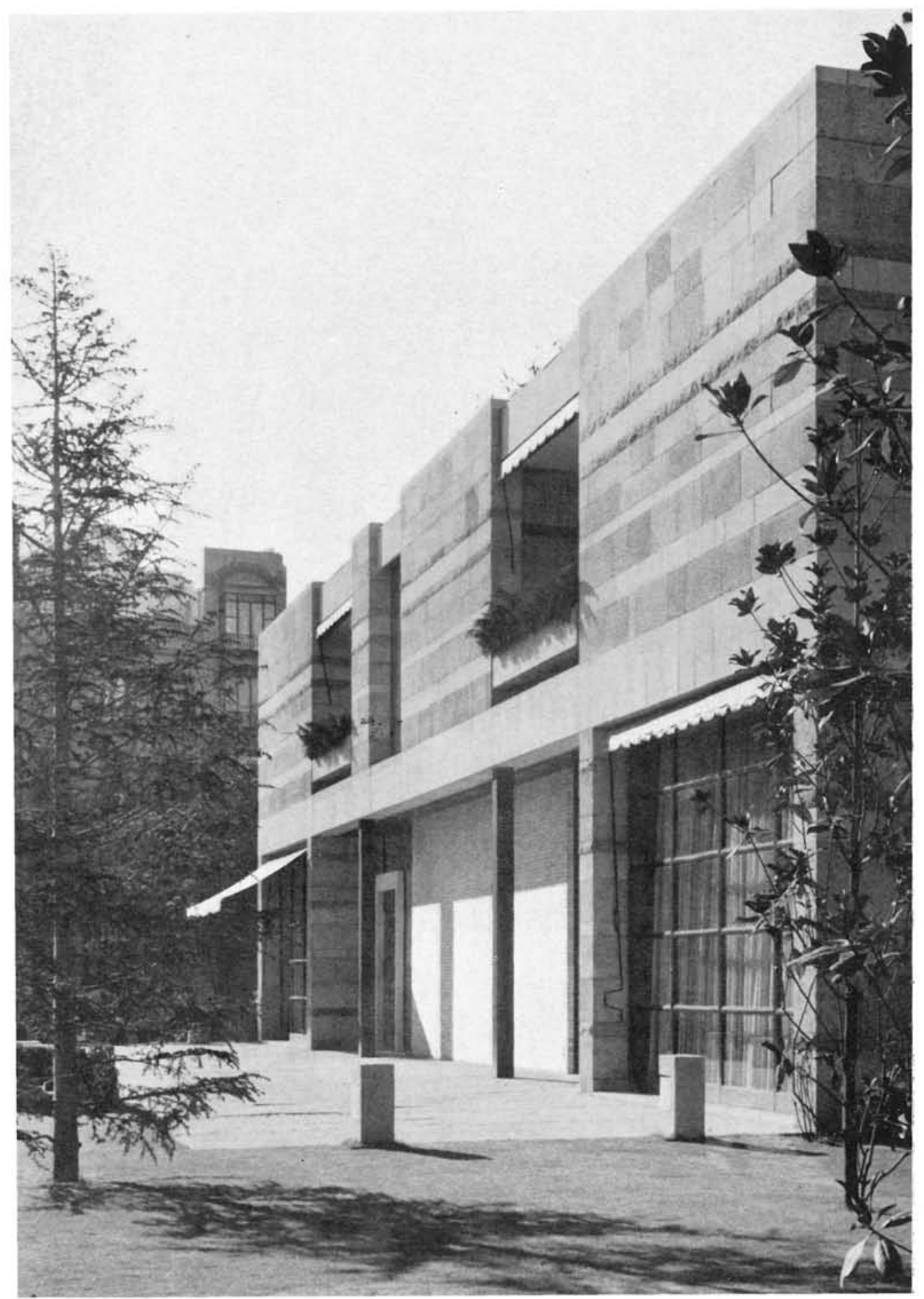

Esta Misión de la República Federal Alemana en Madrid se encuentra situada en el número 25 del Paseo de la Castellana, una de las zonas más señoriales de la capital. En dicho lugar se construyeron los mejores palacios y jardines, incluyendo el de la propia Embajada. Aún hoy en día, la arteria N.-S., llamada Paseo de la Castellana, constituye uno de los puntos más característicos, nobles y espaciosos, del antiguo Madrid que desaparece. 


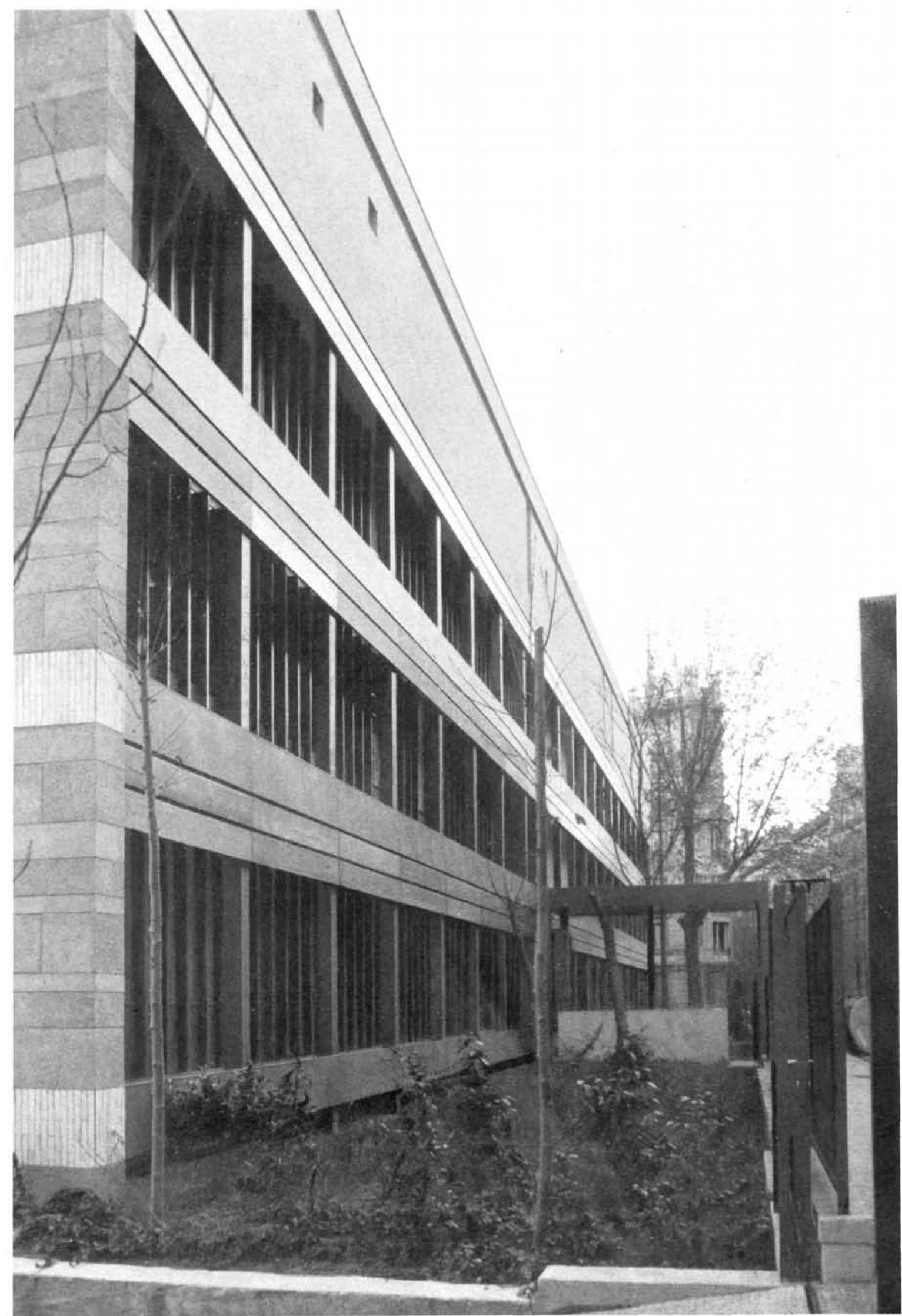



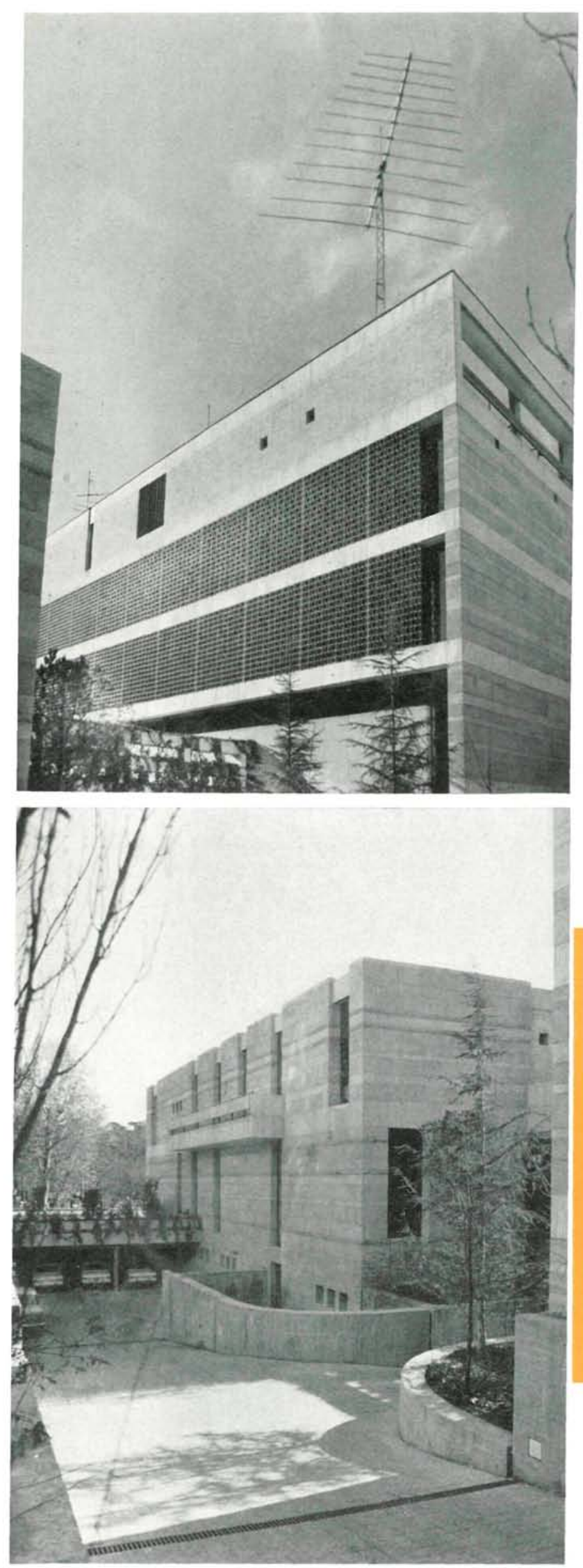

\section{canceilleria}

Esta situación y la categoría especial de los bloques a construir en dicho lugar obligaron a cuidar especialmente el ambiente y carácter de los dos edificios (Cancillería y Residencia), así como el estudiar a fondo la parte de accesos y jardinería.

Las obras se concluyeron totalmente en octubre de 1966.

Superficie edificada:

1) Cancillería $\ldots \ldots \ldots \ldots \ldots \ldots . \quad 925 \mathrm{~m}^{2}$

2) Residencia................ 1.023 »

3) Dedicada a zona verde ..... 6.542 »

\section{ored emecución menerent cllell prongerto}

El edificio de la Cancillería tiene su fachada principal orientada hacia la calle de Fortuny. El cuerpo tiene su eje primario en dirección N.-S., con las oficinas situadas en la parte oeste.

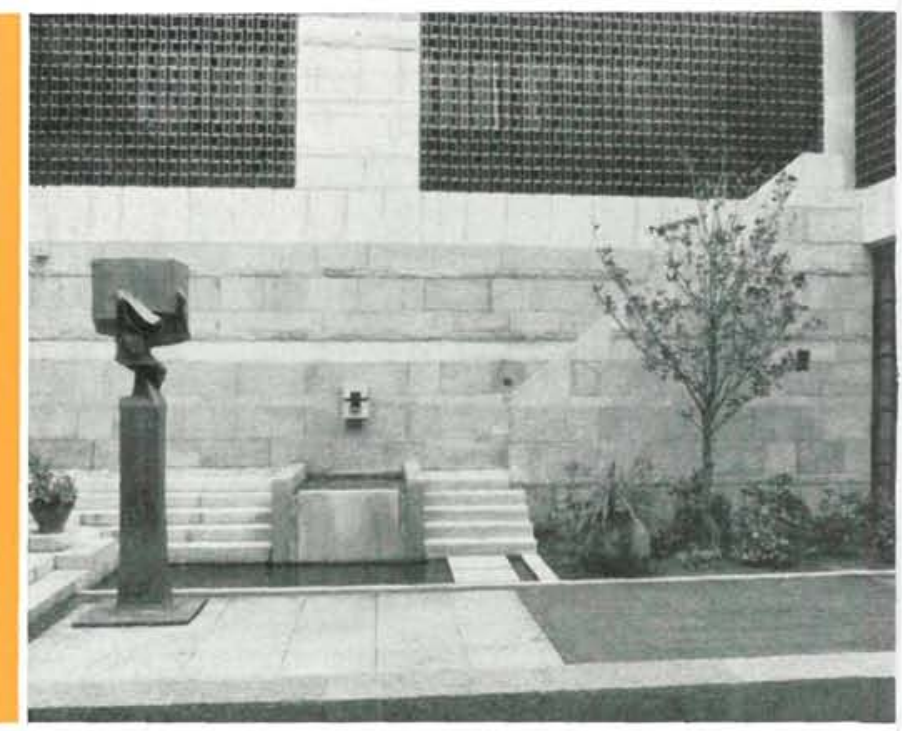

\section{residemcia}



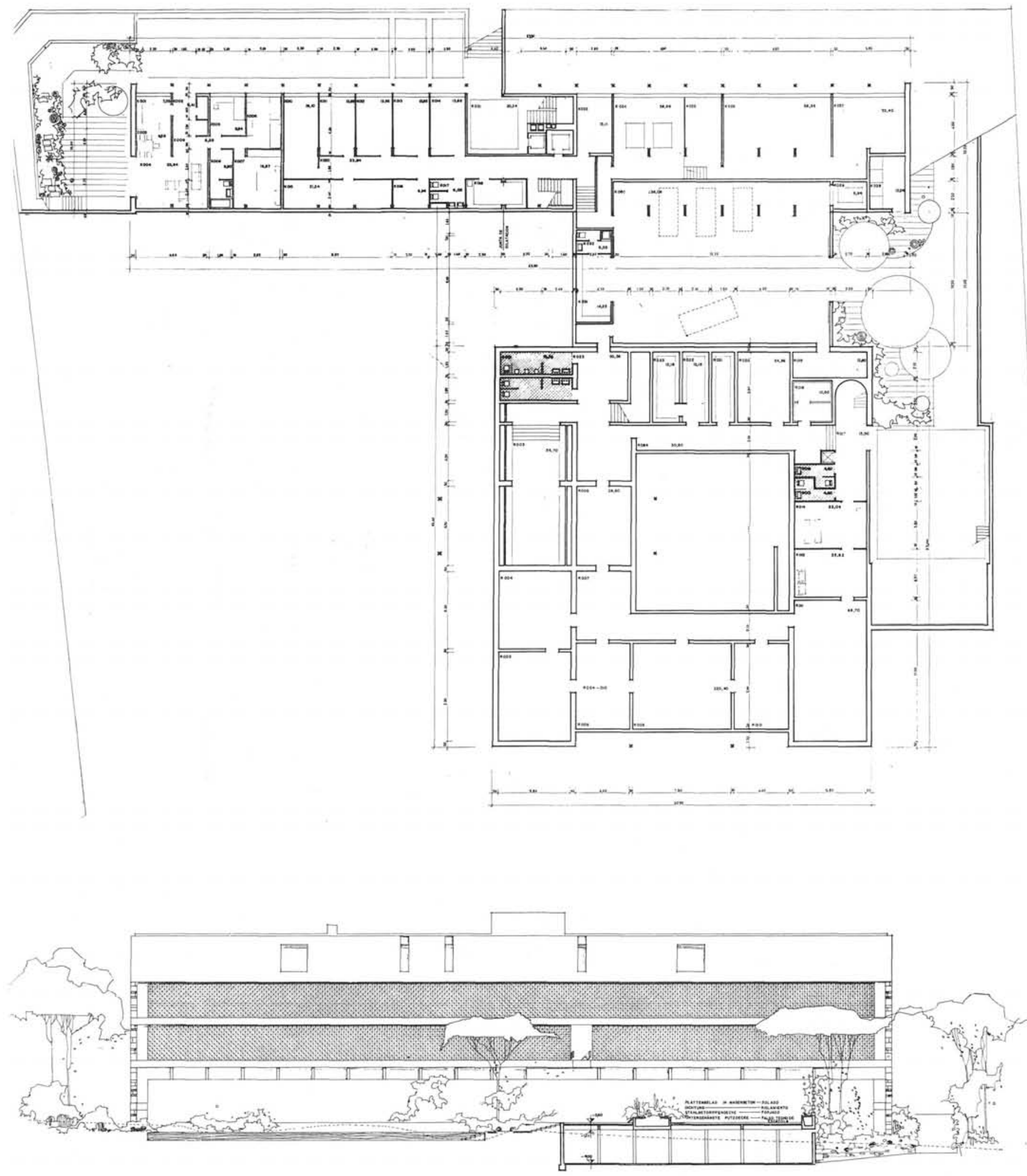

allzando oste 


\section{plantal baja}
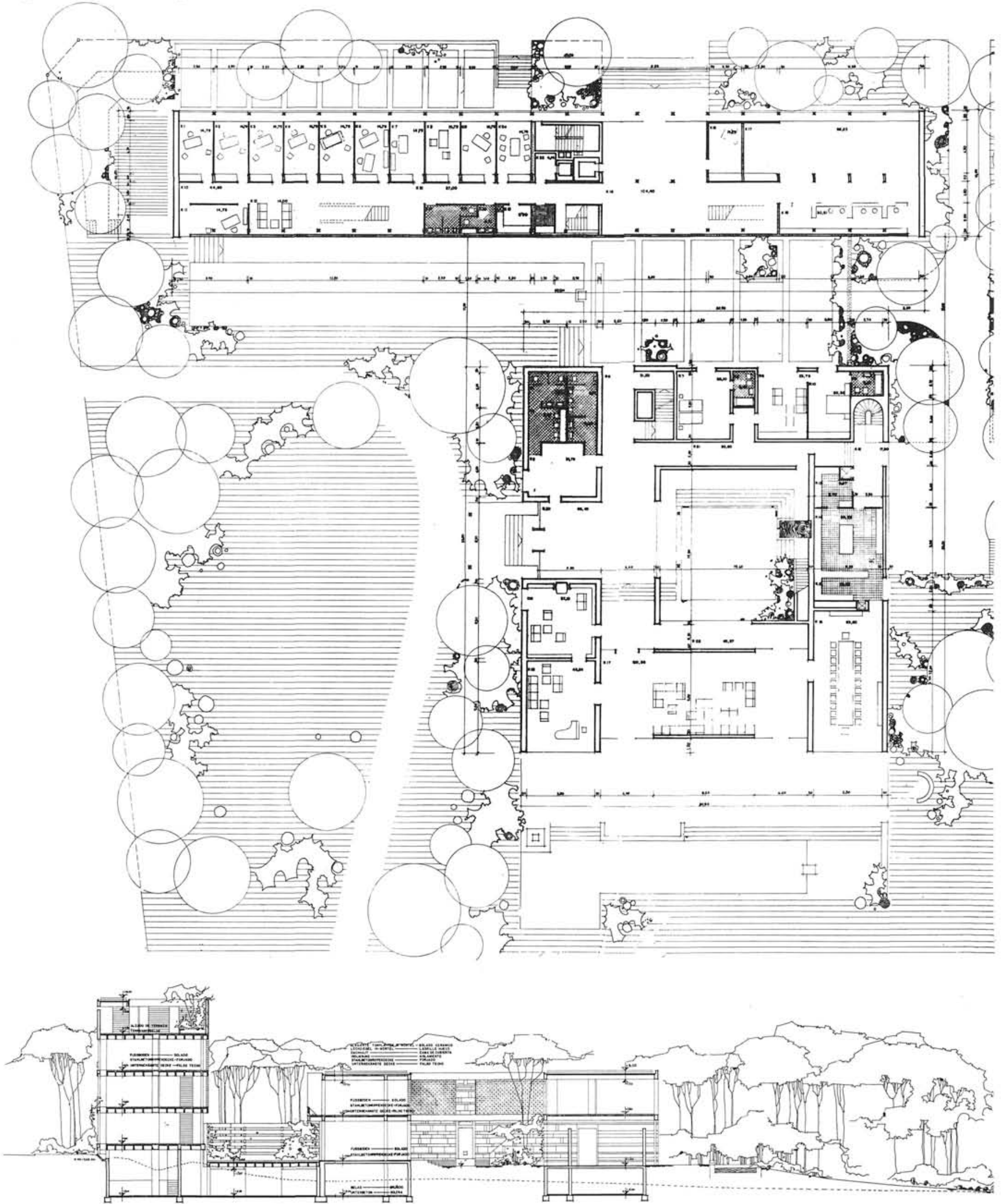

sección 


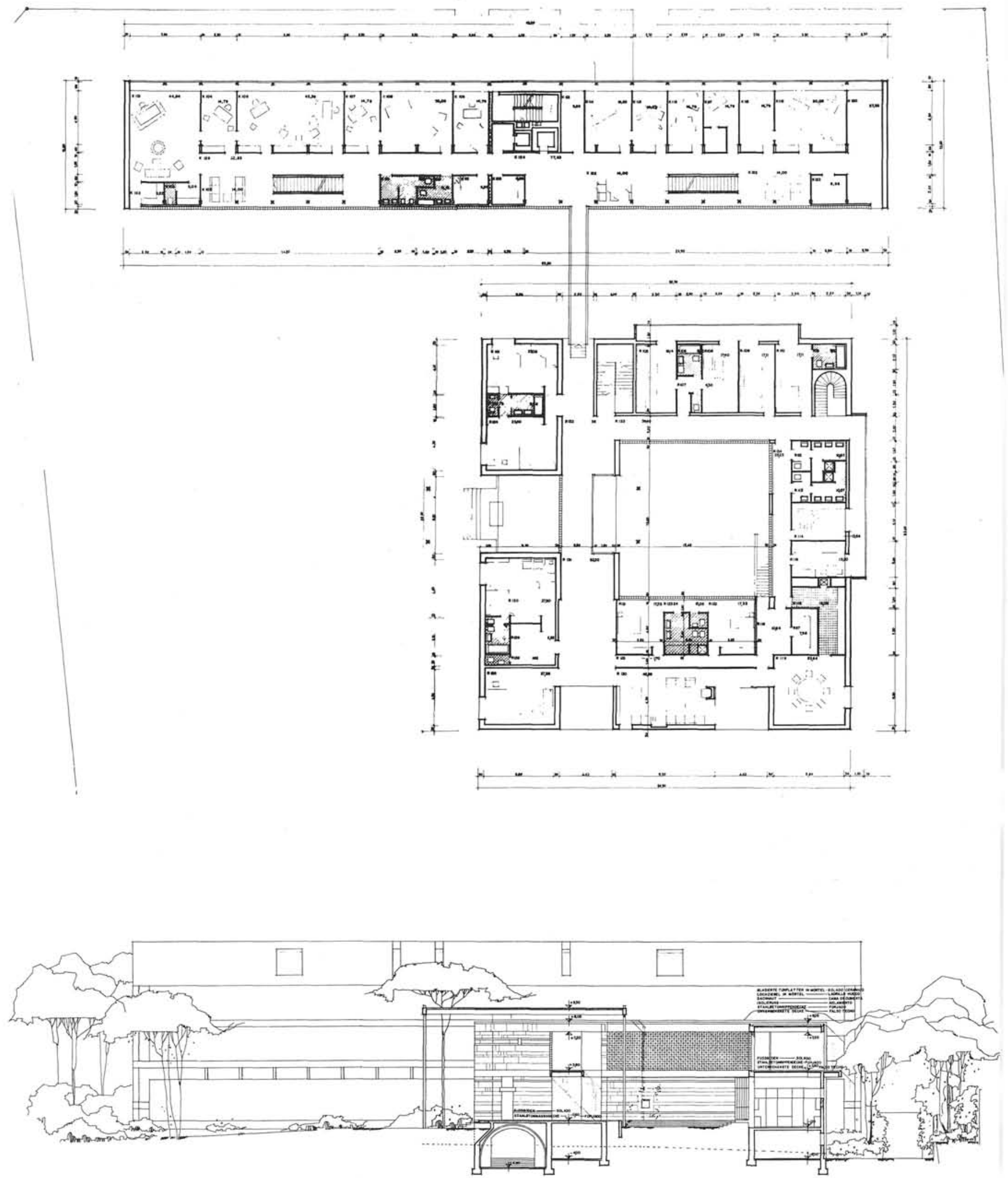

Sección por" rosidumcia y allzaclo este 

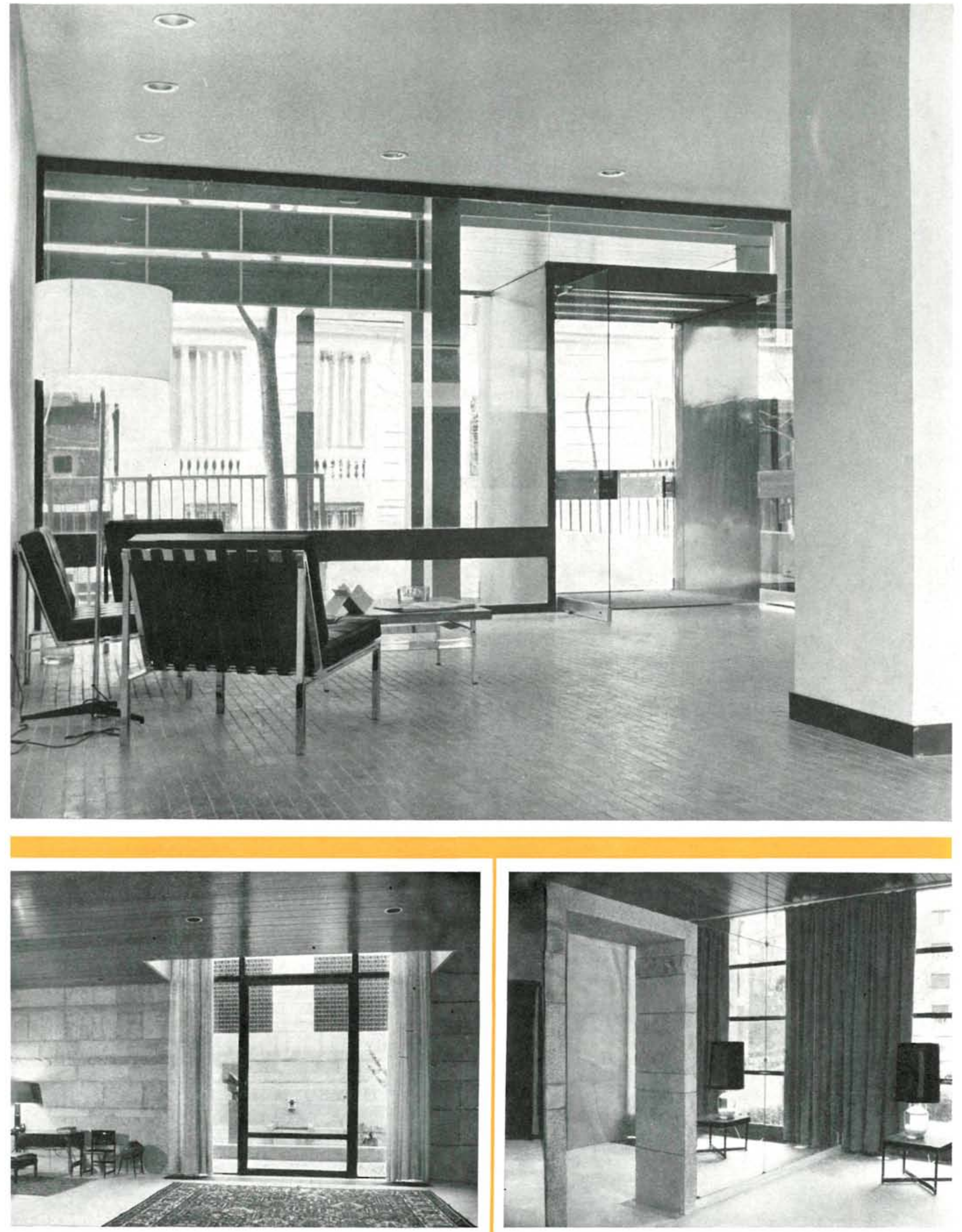
El acceso principal de la Cancillería, así como el de las viviendas existentes en la planta alta, y el acceso a la vivienda del conserje, situada en la planta de semisótano, se realizan desde la calle Fortuny.

La Residencia dispone de una planta de sótano y dos elevadas. La Cancillería consta de: semisótano, planta baja y tres plantas de pisos.

Las viviendas de la tercera planta tienen acceso a través de una escalera y un ascensor propios e independientes.

La Residencia se ubica en la zona NO. de la parcela, que limitan la Cancillería y las edificaciones adyacentes. De esta forma se consiguió crear hacia la Castellana y la calle de Zurbarán una franja bastante ancha (unos $35 \mathrm{~m}$ ) para zona verde. La Residencia tiene su planta baja a unos $3 \mathrm{~m}$ aproximadamente por encima del nivel de la Castellana.

El terreno se halla en pendiente uniforme hacia la Castellana o está adecuadamente aterrazado.

Entre la Cancillería y la Residencia se encuentra, a nivel del sótano, un garaje para unos 6 u 8 coches. El acceso a él, así como al patio de servicios, se hará desde la calle de Fortuny. En este citado patio existen también amplias posibilidades de aparcamiento.

El acceso a la Residencia está proyectado desde la Castellana, y la salida, por la calle de Zurbarán.

El resto se compondrá y plantará en forma de jardín moderno, con grandes tapices verdes, rocallas y grupos arbóreos muy definidos.

Hay previstos estanques en diversos puntos, con misión ornamental y reflectante.

Fue preocupación primordial el conseguir un grupo de edificios en el cual se pudiese albergar dignamente una Misión Diplomática, pero al mismo tiempo lograr algo que encajase en el carácter del país anfitrión.

Dos motivos arquitectónicos se tuvieron en cuenta:

¿ el uso de patios ajardinados interiores;

b el empleo de los materiales típicos del país y la región, como son el granito, las celosías y los materiales cerámicos.

Ambos edificios contienen dichos motivos y sus fachadas muestran los materiales indicados.

La entonación cromática es muy ponderada; masas cremas de la cerámica y del granito de la sierra madrileña, ya algo meteorizado, azules-verdosos oscuros en las celosías vidriadas y zonas metálicas al exterior, acentuado muy parcialmente por los ocres de las celosías en madera de cedro; todo ello rodeado con el eterno y magnífico fondo verde de los céspedes y el arbolado.

Como homenaje al antiguo palacio existente en aquel lugar y destruido durante la Guerra Civil, se ha conservado, restaurándolo con cariño, un pequeño pabellón-templete situado en la confluencia del Paseo de la Castellana con la calle de Zurbarán.

La Embajada, aparte de las instalaciones inherentes a su misión específica, posee una central transformadora, un grupo electrógeno y un abastecimiento de agua propios, éste 
último por un sondeo a $110 \mathrm{~m}$ en el subsuelo del solar.

La estructura, mixta de hormigón, perfiles laminados y muros de carga compuestos, ha sido reducida a secciones mínimas, lográndose cargas de rotura en el hormigón a los 28 días de más de $300 \mathrm{~kg} / \mathrm{cm}^{2}$.

Ambos edificios están totalmente acondicionados y la Residencia dispone de calefacción por aire y por muros radiantes.
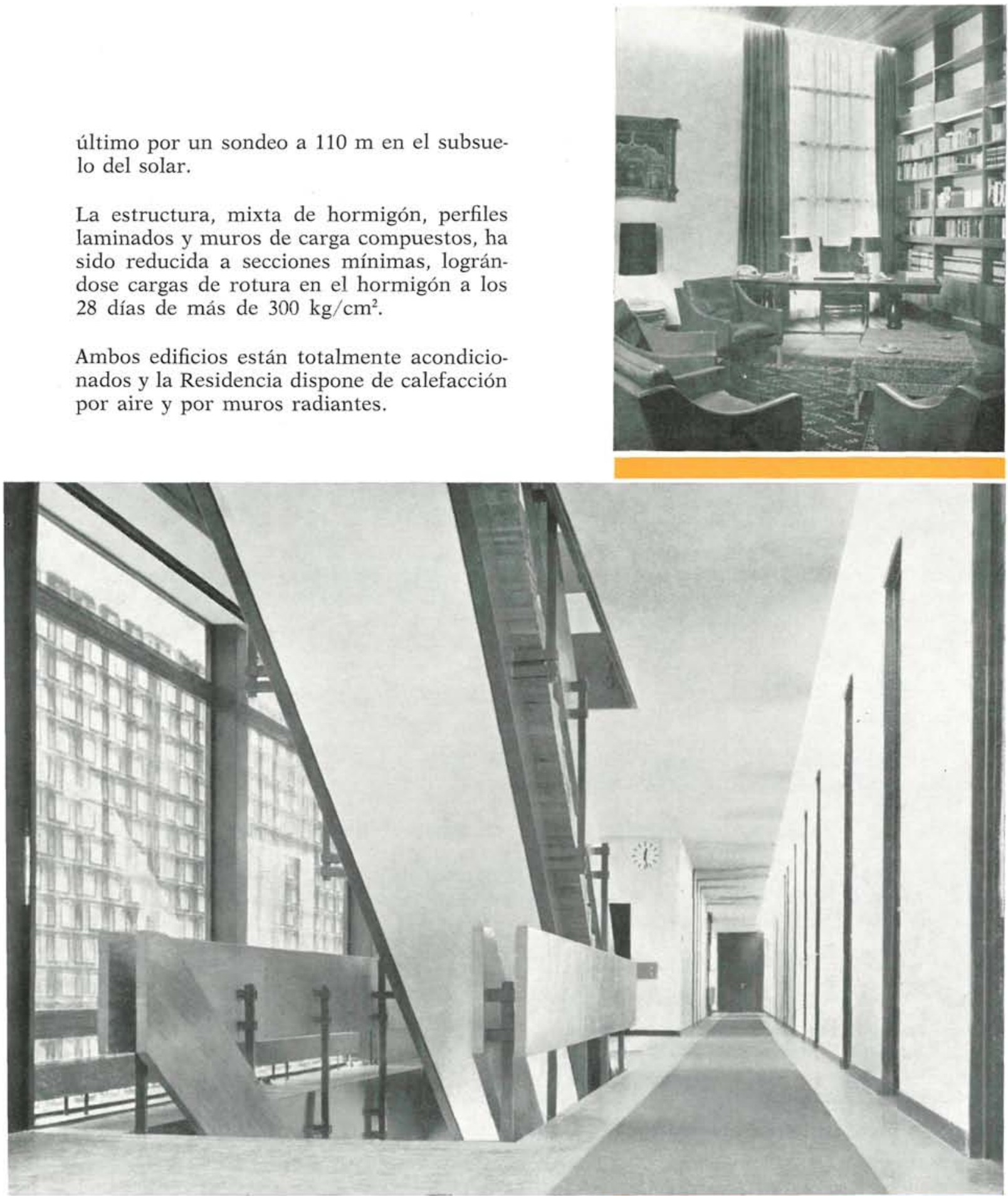

Es de esperar que Alemania, después de 21 años transcurridos desde la última Guerra Mundial, haya conseguido por fin una sede digna en Madrid, que sea a su vez motivo de satisfacción desde el punto de vista arquitectónico para la capital de España y el hermoso Paseo de la Castellana.

Fotos CORBELLA Y CALDERON

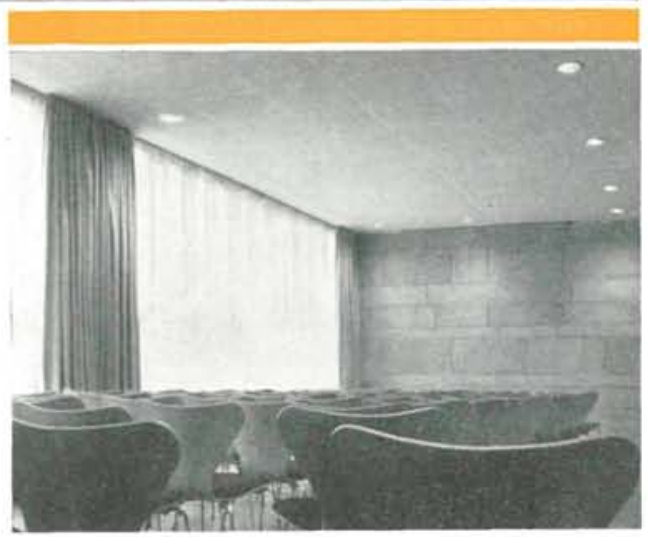




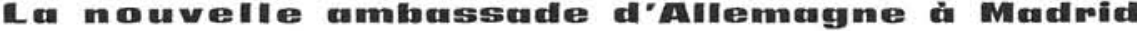

G. Schoebel Ungría, Dr. architecte. Baron v. Branca et M. Bobran, architectes BDA. G. Maasberg, Ing. Dipl. A. Reich, architecte de jardins BDA. F. Koenig, Prof. sculpteur.

Les deux édifices qui composent l'ensemble de cette ambassade constituent, pour la façon dont ils ont été traités, pour leur représentativité, pour le goût avec lequel ils ont été construits et pour le respect témoigné aux volumes de l'espace autorisé, un véritable ornement pour cette zone, une des plus nobles et des plus agréables de la capitale espagnole. Tous les matériaux employés sont les traditionnels de la région et ont été soigneusement choisis et conservés dans toute leur pureté plastique, de caractère et de chromatique.

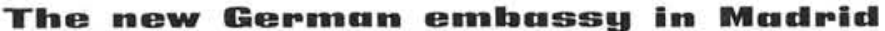

G. Schoebel Ungria, Dr. arch. Baron v. Branca \& M. Bobran, BDA architects. G. Massberg, Dipl. engineer. A. Reich, BDA garden engineer. F. Koenig, Prof. sculpture.

This embassy involves two buildings, which, because of their style, appropriate aspect, the fine taste of their design, and the highly efficient manner in which the volumes agree with the building site, constitutes a singular ornament to one of the best zones of Madrid. All the materials are traditional in Spanish constructional practice, and were carefully chosen: their full plastic and chromatic quality being well utilised.

\section{Die meue deutsche Botschaft in Madrid}

G. Schoebel Ungria, Dr. Architekt. Baron v. Branca und M. Bobran, Architekten BDA. G. Maasberg, Dipl. Ingenieur. A. Reich, Gartenarchitekt BDA. F. Koenig, Bildhauereiprofessor.

Die zwei Gebäude, die den Komplex bilden, sind wegen seiner Behandlung, Repräsentation und wegen des Geschmacks, mit dem sie gebaut wurden, eine besondere Verzierung in einem der elegantesten Stadtviertel der Hauptstadt von Spanien.

Alle angewendeten Materialien sind die traditionellen des Landes und wurden mit Sorgfalt gewählt. 